Bangladesh J. Bot. 40(2): 149-153, 2011 (December)

\title{
PHENOLOGY AND DEGREE DAYS OF RICE CULTIVARS UNDER ORGANIC CULTURE
}

\author{
M R ISLAM AND S SIKDER* \\ Department of Crop Physiology and Ecology, Hajee Mohammad Danesh Science and \\ Technology University, Dinajpur, Bangladesh
}

Key words: Phenology, Growing degree days, Heat use efficiency, Fine rice

\begin{abstract}
Variations in the phenology and degree days of five fine rice cultivars viz., Rajshahi swarna, Silkumul, Kataribhog, Lal pajam and Sanla under organic and inorganic cultural conditions were studied following a split plot design. The requirement of days to attain various phenological stages was highest in Rajshahi swarna, medium in Silkumul, Kataribhog and Lal pajam and the lowest in Sanla for both the cultural conditions. The growing degree days (GDD) and heat use efficiency (HUE) were slightly higher under inorganic than organic culture because of higher life span of rice cultivars in inorganic culture. The highest GDD and HUE were found in Rajshahi swarna, whereas the lowest in Sanla. Results also showed that the requirement of days and GDD were initially higher up to maximum tillering stage under organic culture but thereafter these requirements were greater under inorganic culture for all the cultivars. The grain yield was somewhat lower in organic compared to inorganic culture. In Rajshahi highest grain yield of swarna was 2.90 and $2.74 \mathrm{t} / \mathrm{ha}$ under inorganic and organic culture, respectively.
\end{abstract}

\section{Introduction}

Rice (Oryza sativa L.) is the first ranking cereal in terms of area and production, and transplanted local aman rice including fine rice, aromatic rice and other cultivars grown in 1.66 million hectares of land with the total production of 1.34 million metric tons (BBS 2008). Consumer demands for the fine rice varieties are higher due to its good nutritional quality, palatability, taste, cooking quality and fragrance (Kaul et al. 1982) and cooked on special occasions. Continuous use of inorganic fertilizer had deleterious effects on soil fertility and productivity with steady decline in rice production (Nambiar et al. 1998). Organic fertilizer increases soil microbial activity and improves soil health. A good soil should have at least $2.5 \%$ organic matter, but in Bangladesh most of soils it is less than 1\% (BARC 2005). Some agencies prepare nutrient enriched organic fertilizers, like Moni Mukta, Agro-sar, Jaibo-sar, Super Greenfield, Chook-Chook 111 from cow-dung, FYM and poultry manure and have been evaluated for wetland rice cultivation. It has been observed that fine aromatic rice gradually loses their aroma, yield and taste due to lack of organic matter content in soil, proper cultural management and changes of environment (Singh and Singh 1997). The present study is aimed at studying the phenology and growing degree days of Bangladeshi fine rice cultivars using organic fertilizer.

\section{Materials and Methods}

The experiment was set at the research farm of Crop Physiology and Ecology Department, Hajee Mohammad Danesh Science and Technology University (HSTU), Dinajpur during the aman season (August to December) of 2008. Five fine rice cultivars, viz. Rajshahi swarna, Silkumul, Kataribhog, Lal pajam and Sanla were used and cultivated in a split plot design with three replications. The unit plot size was $6 \mathrm{~m}^{2}(3 \mathrm{~m} \times 2 \mathrm{~m})$ having a plot to plot and block to block

*Corresponding author. 
distance of $0.75 \mathrm{~m}$ and $1.0 \mathrm{~m}$, respectively. There were 30 plots in the experiment. A fertilizer dose of 90-75-60-60-10 kg/ha was applied as $\mathrm{N}, \mathrm{P}_{2} \mathrm{O}_{5}, \mathrm{~K}_{2} \mathrm{O}, \mathrm{S}$ and $\mathrm{Zn}$, respectively in the form of urea, TSP, MOP, gypsum and zinc oxide. Organic fertilizer of Northern Agro Services Ltd. (NASL) was used at the dose of $2 \mathrm{t} / \mathrm{ha}$ which contain $\mathrm{N}, \mathrm{P}_{2} \mathrm{O}_{5}, \mathrm{~K}_{2} \mathrm{O}, \mathrm{S}, \mathrm{Ca}, \mathrm{Mg}, \mathrm{Fe}, \mathrm{Zn}, \mathrm{Mn}$ and $\mathrm{Cu}$ as $4,1.15,1.5,1,2.5,0.75$ and $0.05 \%, 150,170$ and $24 \mathrm{ppm}$, respectively.

Phenological stages include seedling establishment tillering, booting, heading, anthesis, milking, dough and maturity.

The accumulated heat unit system is based on the idea that plants have definite temperature requirements to attain certain phenological stage. The GDD and HUE were calculated following Rajput (1980).

Growing degree days $(\mathrm{GDD})=\sum\left[\left(\mathrm{T}_{\max }+\mathrm{T}_{\min }\right) / 2-\mathrm{T}_{\mathrm{b}}\right]$. Here, $\left(\mathrm{T}_{\mathrm{b}}=\right.$ Base temperature $\left.=10^{\circ} \mathrm{C}\right)$

Heat use efficiency $(\mathrm{HUE})=$ Grain yield $(\mathrm{kg} / \mathrm{ha}) / \mathrm{GDD}$

The treatment means were compared using DMRT as outlined by MSTAT program (Gomez and Gomez 1984).

\section{Results and Discussion}

Phenology of five fine rice cultivars under the cultural conditions of inorganic and organic culture is presented in Table 1. Results indicated that phenology was significantly influenced by the interaction effect of cultural conditions and cultivars. The numbers of days for attaining different phenological stages differed from cultivar to cultivar. In case of organic culture, all the cultivars showed higher requirement of days for attaining seedling establishment, initial and maximum tillering stages compared to inorganic culture. But from booting to harvesting stage, this requirement of days decreased as compared to inorganic culture. It was found that both inorganic and organic culture, the requirement of days to complete various phenological stages like seedling establishment, initial and maximum tillering, booting, heading, anthesis, milking, dough, maturity and harvesting were highest in Rajshahi swarna, medium in Silkumul, Kataribhog and Lal pajam and lowest in Sanla. The results also indicated that the life duration of all the cultivars were significantly shorter in organic than inorganic culture. Similar results were found in fine aromatic strains that the phenological stage (flowering) of IR-8 $\times$ Jajai-77 required minimum (73-77) days, followed by D. Basmati $\times$ Lateefy and Jajai-77 (80 days and 105 days, respectively) due to varietals differences (Oad et al. 2006) and also found that the cultivar Chinigura required highest number of days before booting (83.20), heading (86) and flowering (88.80) as compared to Begunbitchi and Kalijira (Kabir et al. 2004).

The combined effect of cultural conditions and cultivars on heat unit at growing degree days (GDD) was significant at all the phenological stages of rice cultivars (Table 2). The lowest heat unit (GDD) requirement was observed in seedling establishment stage, whereas in the successive phenological stages like initial tillering, maximum tillering, booting, heading, anthesis, milking, dough, maturity and harvesting the heat unit (GDD) increased. All the cultivars showed significantly higher heat unit (GDD) from seedling establishment to maximum tillering stage in organic culture than inorganic culture. But from booting stage to harvesting stage the GDD was increased in inorganic culture. Under both growing conditions Rajshahi swarna required the highest heat unit (GDD) at all the phenological stages which was followed by Silkumul, Kataribhog and Lal pajam, whereas Sanla required lowest heat unit (GDD) at its different phenological stages. The GDD requirement for maturity was highest in Lal Swarna (2385 degrees C/day), followed by IR-36 (1975 degrees C/day) and Kshitish (1913 degrees C/day) (Khan et al. 2006). 


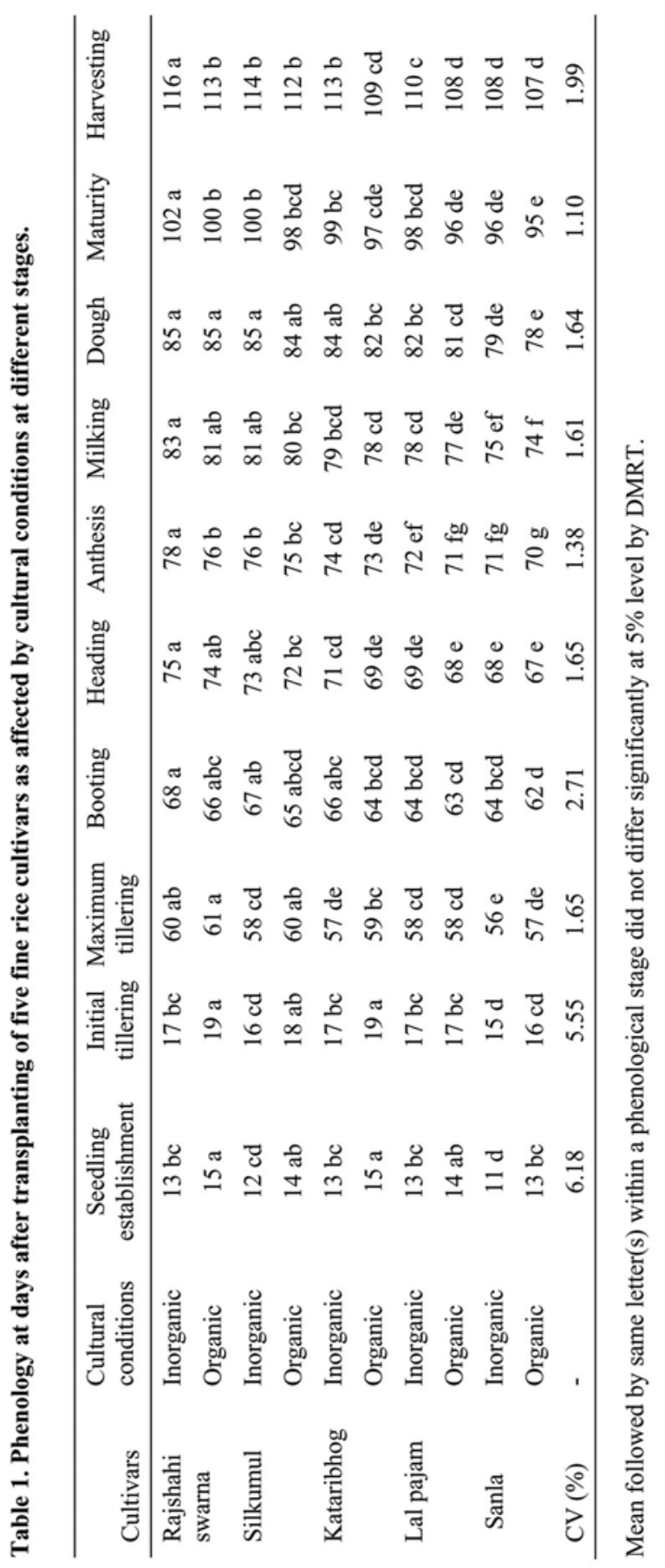




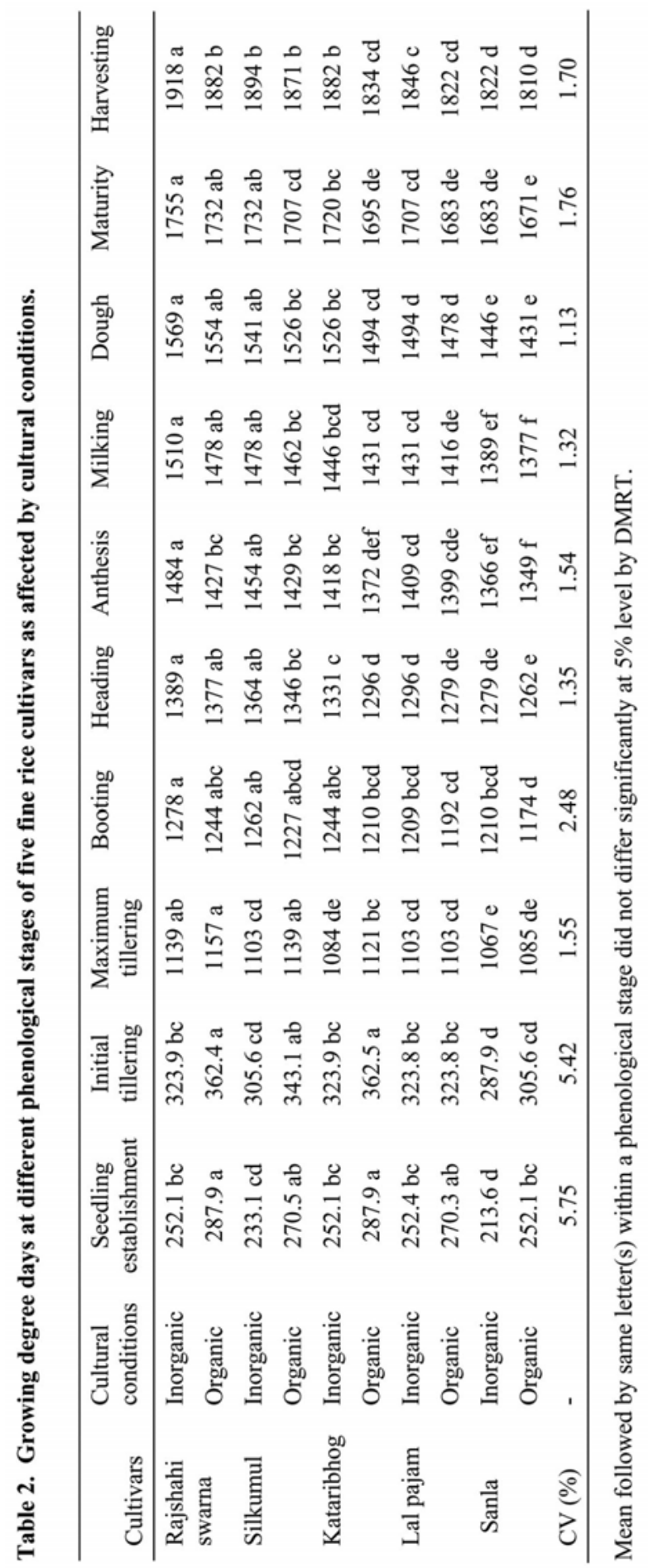


The interaction effect of cultural conditions and cultivars significantly influenced the heat use efficiency in most of the cases (Table 3). Results showed that all the cultivars used heat more efficiently at inorganic as compared to organic culture. Under inorganic culture, Rajshahi swarna and Silkumul showed significantly higher HUE followed by Kataribhog, whereas Sanla and Lal pajam recorded lowest HUE. In case of organic culture, Rajshahi swarna had the highest HUE and Sanla showed the lowest heat use efficiency. The reduction in HUE the Rajshahi swarna and Lal pajam were lower and the highest reduction was found in Sanla followed by Kataribhog and Silkumul.

Table 3. Heat use efficiency of five fine rice cultivars as affected by cultural conditions.

\begin{tabular}{|c|c|c|c|}
\hline \multirow[b]{2}{*}{ Cultivars } & \multicolumn{2}{|c|}{ Heat use efficiency } & \multirow{2}{*}{$\begin{array}{c}\text { Reduction at organic } \\
\text { culture }(\%)\end{array}$} \\
\hline & Inorganic culture & Organic culture & \\
\hline Rajshahi swarna & $1.51 \mathrm{a}$ & $1.45 \mathrm{bc}$ & 3.97 \\
\hline Silkumul & $1.50 \mathrm{ab}$ & $1.30 \mathrm{~d}$ & 13.33 \\
\hline Kataribhog & $1.44 \mathrm{c}$ & $1.20 \mathrm{e}$ & 16.68 \\
\hline Lal pajam & $1.32 \mathrm{~d}$ & $1.25 \mathrm{e}$ & 5.30 \\
\hline Sanla & $1.21 \mathrm{e}$ & $0.96 \mathrm{f}$ & 20.66 \\
\hline CV $(\%)$ & \multicolumn{2}{|c|}{1.18} & - \\
\hline
\end{tabular}

Mean followed by same letter(s) did not differ significantly at $5 \%$ level by DMRT.

Based on phenology, growing degree days, heat use efficiency and yield the farmer should be cultivated the cultivar Rajshahi swarna by using organic fertilizer.

\section{References}

BARC (Bangladesh Agricultural Resaerch Council) 2005. Fertilizer Recommendation Guide. BARC, soils pub. No. 45, Bangladesh Agril. Res. Council, Farmgate, Dhaka.

BBS (Bangladesh Bureau of Statistics) 2008. Bangladesh Bureau of Statistics Agriculture Wing [online]. In: http://www.bbs.gov.bd, 18 July 2008. People's Republic of Bangladesh, Dhaka.

Gomaz KA and AA Gomaz 1984. Statistical Procedure for Agricultural Research. Intl. Rice Res. Inst. John Wiley, New York. 139 pp.

Kabir ME, MHA Rashid and MS Jahan 2004. Yield performance of three aromatic fine rice in a coastal low land. Pak. J. Bio. Sci. 7(9): 1526-1529.

Kaul AK, MRI Khan and KM Munir 1982. Rice quality: a survey of Bangladesh Germplasm. Bangladesh Rice Res. Inst., Joydebpur, Gazipur. 178 pp.

Khan TN, A Razzaq, M Shahbaz, S Ajmal, GM Ali and MF Joyia 2006. Performance of four varieties of fine rice for best yield and yield components under climatic conditions of Bahawalpur (Pakistan). J. Agril. Soc. Sci. 2(3): 187-188.

Nambiar KKM, J Sehgal, WE Blum and KS Gojbhiya 1998. Ingreted use of organic manures and chemical fertilizer in red soils for sustainable agriculture. Indian J. Agric. Sci. 2(1): 367-376.

Oad GL, FC Oad, AA Bhand and MH Siddiqui 2006. Performance of aromatic rice strains for growth and yield potentials. Asian J. Plant Sci. 5(3): 531-533.

Rajput RP 1980. Response of soybean crop to climate and soil environment. Ph. D. Thesis. IARI, New Delhi.

Rohilla R, VP Singh, US Singh, RK Singh and GS Khush 2000. Crop husbandry and environment factors affecting aroma and other quality traits. In: Aromatic Rice, DP Singh, ad UN Verma (Eds), 201-216 pp. Oxford \& IBH Publishing Co. Pvt. Ltd. New Delhi.

Singh RK and US Singh 1997. Indigenous scented rices: farmers perception and commitment. Paper presented at International Conference on Creativity and Innovation at Grassroots, January 14-17, 1997, Hyderabad. 